\title{
Avaliação do efeito bacteriostático das folhas do lúpulo para tratamento de dejetos bovinos
}

O lúpulo é uma planta perene de crescimento rápido e comum em regiões de clima temperado. Os cones são usados na indústria cervejeira, pois suas glândulas secretam lupulinas, as quais contém alfa e beta ácidos responsáveis por dar aroma e amargor à cerveja, além de conservá-la. O Brasil é um dos maiores criadores de gado no mundo, gerando grande volume de dejetos nos quais há diversos tipos de patógenos. O reaproveitamento dos resíduos do lúpulo como possível agente antimicrobiano no tratamento dos dejetos bovinos pode ser uma alternativa sustentável para produtores rurais. A ação bacteriostática do lúpulo foi avaliada para o pool de bactérias isoladas de dejetos bovinos armazenados a $-20^{\circ} \mathrm{C}$ até a realização do experimento. Por infusão durante 48 horas, foram preparados extratos aquosos das folhas do lúpulo cultivados em 2 tipos de solos (misto e arenoso), com $4 \mathrm{~h}$ em homogeneização no shaker a $90 \mathrm{rpm}$, e esterilizados por filtração. No teste bacteriológico, a partir da concentração inicial de $0,28 \mathrm{~g} / \mathrm{mL}$, foram realizadas 5 diluições seriadas em triplicatas com $10 \mu \mathrm{L}$ da suspensão bacteriana. Após $24 \mathrm{~h}$ de incubação à $37^{\circ} \mathrm{C}$ avaliou-se o crescimento bacteriano (visual e Pour Plate). Os resultados indicaram um crescimento acima de 10 mil unidades formadoras de colônia em todas as diluições, impossibilitando a quantificação, ou seja, nas concentrações testadas os extratos não apresentaram ação bactericida sobre a microbiota avaliada. Dessa forma, em vista dos resultados, é necessário estabelecer a concentração limite para viabilizar a ação bacteriostática do extrato do lúpulo em dejetos bovinos

Palavras-chave: Humulus Lupulus; Bactericida; Resíduos agrícolas; Dejeto Bovino.

\section{Evaluation of the bacteriostatic effect of hop leaves for the treatment of bovine waste}

\begin{abstract}
Hops are a fast-growing perennial plant common in temperate countries. The cones are used in the brewing industry, as their glands secrete the substance lupulins, which contain alpha and beta acids responsible for giving aroma and bitterness to beer, in addition to conserving it. Brazil is one of the largest cattle breeders in the world and consequently generates a large volume of manure, which contains several pathogens. The reuse of hops crop residues as a possible antimicrobial agent in the treatment of bovine manure can be a sustainable alternative for small rural producers. The bacteriostatic action of the hops was evaluated from the pool of bacteria isolated from bovine manure and were stored at $-20^{\circ} \mathrm{C}$ until the experiment was carried out. By means of infusion for 48 hours, aqueous extracts of the leaves of the hops grown in 2 types of soil (mixed and sandy) were prepared, with 4 hours in homogenization in the shaker at 90 rpm and sterilized by filtration. For the bacteriological test, from the initial concentration of $0.28 \mathrm{~g} / \mathrm{mL}, 5$ serial dilutions were performed in triplicates with $10 \mu \mathrm{L}$ of the bacteria suspension. After 24 hours of incubation at $37^{\circ} \mathrm{C}$, bacterial colonies were counted (visual and Pour Plate). The results indicated a growth above 10,000 colonyforming units in all dilutions, making quantification impossible, that is, in the tested concentrations the extracts did not show bactericidal action on the evaluated microbiota. Thus, given the results, it is necessary to establish the limit concentration to enable the bacteriostatic action of the hops extracts in bovine manure.
\end{abstract}

Keywords: Humulus Lupulus; Bactericide; Agricultural Waste; Bovine manure.

\section{Topic: Microbiologia Agrícola e Ambiental}

Reviewed anonymously in the process of blind peer
Received: 02/08/2020

Approved: $19 / 09 / 2020$
Willian de Almeida Corrêa Machado (D)

Universidade Estadual Paulista, Brasil

http://lattes.cnpq.br/8539906567775593

http://orcid.org/0000-0003-3952-0014

willian.machado@unesp.br

Valeria Cristina Rodrigues Sarnighausen (iD

Universidade Estadual Paulista, Brasil

http://lattes.cnpq.br/0734394320595118

http://orcid.org/0000-0003-3943-0211

valeria.sarnighausen@unesp.br

Alexandre Dal Pai (iD)

Universidade Estadual Paulista, Brasil

http://lattes.cnpq.br/9708248454957558

http://orcid.org/0000-0002-1283-901X

dal.pai@unesp.br

\author{
Rejane Maria Tommasini Grotto (iD \\ Universidade Estadual Paulista, Brasi \\ http://lattes.cnpq.br/77888448564326585 \\ http://orcid.org/0000-0002-4035-9486 \\ rejane.grotto@unesp.br \\ Sergio Augusto Rodrigues (iD \\ Universidade Estadual Paulista, Brasil \\ http://lattes.cnpq.br/6872765214523974 \\ http://orcid.org/0000-0002-2091-2141 \\ sergio.rodrigues@unesp.br
}

Referencing this:

MACHADO, W. A. C.; SARNIGHAUSEN, V. C. R.; DAL PAI, A.; GRTTO, R. M. T.; RODRIGUES, S. A.. Avaliação do efeito bacteriostático das folhas do lúpulo para tratamento de dejetos bovinos. Revista Ibero Americana de Ciências Ambientais, v.11, n.5, p.140-148, 2020. DOI: http://doi.org/10.6008/CBPC2179-6858.2020.005.0015

DOI: 10.6008/CBPC2179-6858.2020.005.0015 


\section{INTRODUÇÃO}

O uso de plantas para fins medicinais é realizado desde o início da civilização. Ao longo dos anos, este tema vem ganhando importância. Atualmente muitas pesquisas estão direcionadas ao uso completo das plantas, não se limitando ao estudo apenas da raiz, caule ou folhas, mas sim estudar cada parte, entendendo suas particularidades e benefícios.

O lúpulo é uma planta perene de desenvolvimento relativamente rápido, chegando a mais de sete metros em cinco meses, pertencente à família Cannabaceae classificada no gênero Humulus, que engloba plantas como a maconha e a amora, do gênero Cannabis e Celtis, respectivamente (SOUSA, 2005). Seu cultivo é mais comum em regiões de clima temperado (Hemisfério Norte) devido às especificidades para um plantio ideal e de qualidade, como baixas temperaturas no período de dormência da semente, receber em torno de 13 horas de fotoperíodo durante desenvolvimento da planta e características inerentes ao solo (NOVAES et al., 2019).

Devido a estas características de cultivo, solo e clima, acreditava-se ser impossível a cultura em larga escala desta planta em solo brasileiro. Porém os resultados de algumas regiões com plantio de lúpulo (Estados do Sul, São Paulo, Rio de Janeiro, Mato Grosso e Bahia) e estudos recentes indicam a adaptação da planta ao solo e clima local.

Uma região de sucesso no plantio do lúpulo foi na Serra da Mantiqueira, onde o clima aparentemente é bastante favorável ao plantio. Após diversas tentativas, a partir de 2011, um produtor de São Bento do Sapucaí conseguiu bons resultados a partir de um exemplar resistente, do qual foram criados clones para iniciar o trabalho com a nova cultura. A partir de 2017 conseguiu uma produção de 2 mil quilos de lúpulo por ano aproximadamente, com colheita realizada no início do outono (no mês de março) no Hemisfério Sul. Na indústria cervejeira é de interesse apenas as inflorescências femininas, pois suas glândulas secretam uma substância chamada lupulina, onde há concentrações de resinas produtoras do alfa e beta ácidos, responsáveis por dar amargor, aroma e conservar a cerveja (ALMAGUER et al., 2014).

Alguns estudos da literatura apontam que outras partes da planta como caule e folhas, também apresentam concentrações de lupulina, mesmo que em menor quantidade. Estudos recentes mostram que os alfa e betas ácidos, presentes em maiores concentrações nos cones e com indícios de sua presença também nas folhas e caules, são efetivos na ação bacteriostáticas, principalmente contra bactérias Gram positivas. Assim, percebe-se que o lúpulo pode ser utilizado em diversas outras aplicações além de seu uso no mercado cervejeiro, entre elas, aplicações voltadas ao uso medicinal, antioxidante e bactericida (SUGIYAMA et al., 2006; ABRAM et al., 2015; BUTU et al., 2016; SANTOS, 2018).

Como cosmético, pelas propriedades antioxidantes, anti-inflamatórias e bacteriostática, destaca os efeitos do extrato do lúpulo em bactérias causadoras da acne, podendo ser utilizado como uma alternativa para tratamento de pele (WEBER et al., 2019), bem como seu uso histórico como produto para redução da queda ou crescimento capilar (KOETTER et al., 2010). Zanoli et al. (2008) destacam um produto da degradação oxidativa dos alfa ácidos, o 2-methyl-3-buten-2-ol, responsável por atividade sedativa, enquanto 
que Franco et al. (2012) avaliaram o efeito sedativo do lúpulo em cervejas sem álcool, levando em consideração a qualidade do sono da população estudada após o consumo da cerveja. Em medicina, observou-se trabalhos com a utilização do lúpulo para auxiliar no tratamento da menopausa, sendo recomendado à reposição hormonal devido à presença de estradiol em extratos etanólicos de lúpulo (CHADWICK et al., 2006; SCHICK et al., 2018) e a possibilidade de extração de componentes para uso terapêuticos contra o câncer, mais precisamente o câncer colorretal e hepático (LOGAN, et al., 2019).

Desta forma, vislumbra-se aplicações em diversas áreas, entre elas, destaca-se a utilização do lúpulo como agente no tratamento de dejetos. No contexto de produção agropecuária, o Brasil é um dos maiores criadores de gado do mundo e muitas propriedades estão localizadas próximas a rios, para facilitar o fornecimento de água para o rebanho e uso cotidiano, além de muitas apresentarem outros usos de suas terras (alguma criação e diferentes culturas agrícolas).

Sabendo que os dejetos de bovinos contêm patógenos que podem ser prejudiciais à saúde e ao meio ambiente, o melhor reaproveitamento de resíduos agrícolas e de dejetos são essenciais para uma produção mais sustentável, além de possibilitar a minimização dos riscos sanitários e a poluição das águas superficiais e subterrâneas, no caso de manejo não apropriado. Atualmente, muitos produtores utilizam antibacterianos para tratamento ou prevenção de doenças em bovinos, possibilitando o surgimento de bactérias resistentes, as quais são secretadas junto as fezes do animal (ARIAS et al., 2012).

Assim, o presente estudo tem como objetivo a avaliação da capacidade antibacteriana de resíduos do lúpulo em bactérias presentes nos dejetos bovinos, possibilitando sua utilização como inibidor de patógenos para melhor reaproveitamento dos dejetos no meio rural. Destaca-se que ainda não há um referencial acerca da concentração do extrato extraído das plantas de lúpulo que possam iniciar ações bacteriostáticas (impedir o crescimento de colônias de bactérias) de dejetos bovinos. Dessa forma, este estudo é um ajuste de referencial para os demais ensaios experimentais futuros.

\section{MATERIAIS E MÉTODOS}

As folhas de lúpulo utilizadas neste estudo foram do cultivar Cascade, obtidas a partir da poda das plantas de um dos experimentos realizados pelo Grupo de Pesquisa Lúpulo: Aplicações e Manejo (LUPAM) do Departamento de Bioprocessos e Biotecnologia da Faculdade de Ciências Agronômicas da UNESP de Botucatu. As mudas foram doadas por produtor do estado de São Paulo em fevereiro de 2018, e a poda foi realizada em março de 2019. Os resíduos de lúpulo (folhas) utilizados foram oriundos de um experimento preparado para avaliar o desenvolvimento e consumo hídrico do lúpulo em um ambiente protegido com solos misto (de textura média) e arenoso (SOUSA et al., 2019).

\section{Preparo do Extrato}

As folhas do lúpulo de ambos os tipos de solo foram trituradas, maceradas e pesadas em balança analítica, obteve-se 43,5147 gramas do lúpulo de solo misto e 43,5144 gramas do lúpulo de solo arenoso. Em seguida, submetidas, separadamente, a infusão em $150 \mathrm{~mL}$ de água aquecida a $60^{\circ} \mathrm{C}$ por $48 \mathrm{~h}$. Foram 
armazenadas em frascos de cultura de $500 \mathrm{~mL}$ selados com papel alumínio e plástico preto, protegendo-os da luz, em geladeira a $4^{\circ} \mathrm{C}$. E neste período foram submetidos a agitação em shaker a $90 \mathrm{rpm}$ por $4 \mathrm{~h}$. A concentração final foi de $0,28 \mathrm{~g} / \mathrm{mL}$ em cada extrato.

\section{Extração e esterilização}

Os extratos foram filtrados em um sistema a vácuo por duas vezes cada, para melhor separação do líquido e da massa úmida. A esterilização também foi realizada em filtração a vácuo, em filtros com membrana de $0,22 \mu \mathrm{m}$. Ao final obteve-se cerca de $80 \mathrm{~mL}$ de cada extrato, que até o momento do teste bacteriológico ficaram armazenados a $4^{\circ} \mathrm{C}$ na geladeira do laboratório de Microbiologia do Departamento de Bioprocessos e Biotecnologia da Faculdade de Ciências Agronômicas - UNESP Botucatu. Os recipientes foram envoltos por plástico preto, para protegê-los da luz.

\section{Crescimento bacteriano e preparo do meio de cultura}

A ação bacteriostática foi avaliada a partir do pool de bactérias isoladas a partir dos dejetos de bovinos da raça Nelore, coletados na Fazenda Experimental de Zootecnia da Unesp Botucatu por Souza et al. (2017), o qual foi congelado em criotubos com glicerol, a $-20^{\circ} \mathrm{C}$, no laboratório de Microbiologia do Departamento de Bioprocessos e Biotecnologia da Faculdade de Ciências Agronômicas - UNESP Botucatu. $O$ isolamento do pool de bactérias presentes nos dejetos seguiu a metodologia proposta por Nascimento et al. (2017) e Souza et al. (2017), considerando todas as normas de segurança individual e para o meio ambiente, evitando possíveis erros experimentais.

Para o crescimento bacteriano, em um tubo com 9,9 mL de meio líquido $\mathrm{BHI}$ foi acrescido $100 \mu \mathrm{L}$ da suspensão bacteriana congelada anteriormente. Posteriormente, o tubo com meio líquido e bactéria permaneceu na estufa por $24 \mathrm{~h}$ anteriores ao experimento. Antes dos testes da ação bacteriostática das folhas do lúpulo, foram preparados 30 tubos de meio BHI (15 tubos para cada extrato) com 9,9 mL cada. A quantidade necessária para o preparo foi pesada em balança analítica e os tubos com meio foram autoclavados para esterilização.

\section{Teste da ação bacteriostática}

As análises microbiológicas foram realizadas no laboratório de Microbiologia do Departamento de Bioprocessos e Biotecnologia da Faculdade de Ciências Agronômicas - UNESP Botucatu, considerando todas as normas de segurança individual e para o meio ambiente, evitando possíveis erros de medida/experimentais.

Em câmara de fluxo laminar (previamente higienizada com álcool 70\% e luz UV ligada por 10 minutos ininterruptos) foram feitas 5 diluições de cada extrato, $10^{-2}, 10^{-4}, 10^{-6}, 10^{-8}, 10^{-1}$, a partir do extrato puro como o $10^{0}$ (porção mais concentrada), utilizando os tubos com meio BHI que foram preparados previamente. Em cada tubo contendo lúpulo diluído foi adicionado $100 \mu \mathrm{L}$ de suspensão bacteriana. Para 
diminuir as chances de erro durante o experimento, as diluições foram feitas em triplicatas (Figura 1).

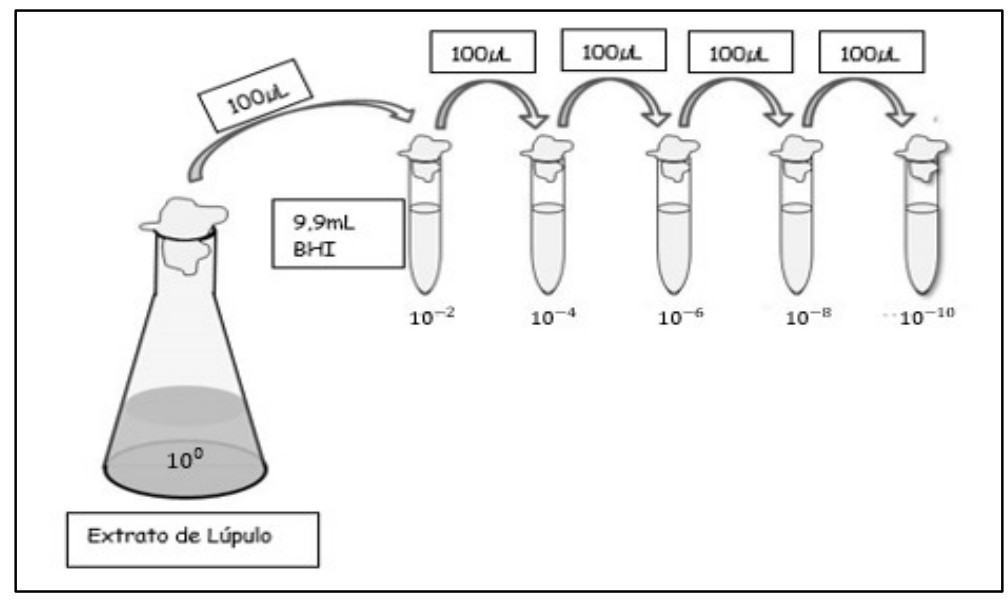

Figura 1: Esquema de diluições do extrato de lúpulo

Foram utilizados três controles: um contendo apenas água e a bactéria para controle de crescimento; outro somente com extrato de lúpulo diluído para controle de esterilidade e um apenas com o meio de cultivo para controle negativo padrão. As amostras foram incubadas a $37^{\circ} \mathrm{C}$ por $24 \mathrm{~h}$ e, após esse período, foram analisadas a turvação, visualmente e utilizando um espectrofotômetro da marca BEL, modelo UV-M51, na faixa de $600 \mathrm{~nm}$, específica, para análise do crescimento de bactérias em presença do extrato.

Posteriormente, foi realizada a técnica de Pour Plate para contagem do crescimento bacteriano. As placas de Petri utilizadas foram previamente autoclavadas e secas em estufa. O meio de cultivo, ágar nutriente, foi preparado no dia em que foi feito o Pour Plate, o qual também foi esterilizado por meio de autoclavação. Para que o meio de cultura permanecesse líquido foi necessário o uso de uma manta elétrica com temperatura mantida em torno de $45^{\circ} \mathrm{C}$, evitando assim que o meio se solidificasse, podendo causar algum dano a bactéria. As placas ficaram em estufa por $24 \mathrm{~h}$ e depois armazenadas a $4^{\circ} \mathrm{C}$ na geladeira para posteriormente realizar a contagem das unidades formadoras de colônia (UFC).

\section{RESULTADOS E DISCUSSÃO}

\section{Avaliação da turbidez}

Ao avaliar visualmente a turbidez dos tubos de ensaio, não foi possível identificar alterações quanto ao crescimento bacteriano (todas amostras apresentaram a mesma turvação). Assim, para uma análise mais conclusiva quanto a turbidez, utilizando um espectrofotômetro, mediu-se a absorbância de duas amostras de cada triplicada. Após calibrar o equipamento com o branco (meio BHI com extrato), ajustou-se o comprimento de onda para $600 \mathrm{~nm}$. Os valores obtidos de absorbância (u.a) das amostras, apresentados nas Tabelas 1 e 2, indicam que não houve grande variação quanto a turbidez e, consequentemente, quanto ao crescimento bacteriano entre as diluições. 
Tabela 1: Absorbância de duas repetições de cada diluição (extrato de folhas de lúpulo plantado em solo misto + suspensão bacteriana).

\begin{tabular}{|c|c|c|c|}
\hline \multirow{2}{*}{ Diluições } & \multicolumn{3}{|c|}{ Absorbância (u.a) em cada repetição } \\
\hline & Repetição 1 & Repetição 2 & Média \\
\hline $10^{-2}$ & 1,543 & 1,586 & 1,565 \\
\hline $10^{-4}$ & 1,545 & 1,610 & 1,578 \\
\hline $10^{-6}$ & 1,480 & 1,580 & 1,530 \\
\hline $10^{-8}$ & 1,536 & 1,590 & 1,563 \\
\hline $10^{-10}$ & 1,579 & 1,610 & 1,595 \\
\hline Branco & 0,020 & & \\
\hline
\end{tabular}

Tabela 2: Absorbância de duas repetições de cada diluição (extrato de folhas de lúpulo plantado em solo arenoso + suspensão bacteriana).

\begin{tabular}{|c|c|c|c|}
\hline \multirow{2}{*}{ Diluições } & \multicolumn{3}{|c|}{ Absorbância (u.a) em cada repetição } \\
\hline & Repetição 1 & Repetição 2 & Média \\
\hline $10^{-2}$ & 1,503 & 1,656 & 1,580 \\
\hline $10^{-4}$ & 1,549 & 1,504 & 1,527 \\
\hline $10^{-6}$ & 1,601 & 1,520 & 1,561 \\
\hline $10^{-8}$ & 1,494 & 1,577 & 1,536 \\
\hline $10^{-10}$ & 1,482 & 1,650 & 1,566 \\
\hline Branco & 0,020 & & \\
\hline
\end{tabular}

\section{Avaliação do crescimento bacteriano}

Todas as triplicatas das placas petri das diluições e tipos de solo avaliados apresentaram um perfil semelhante quanto ao crescimento bacteriano. As imagens apresentadas nas Figuras 2 e 3 mostram o crescimento bacteriano de uma das replicações das placas em cada diluição de suspensão bacteriana $\left(10^{-2}\right.$, $10^{-4}, 10^{-6}, 10^{-8}, 10^{-10}$ ) com o extrato de folhas de lúpulo cultivado em solo misto e arenoso.

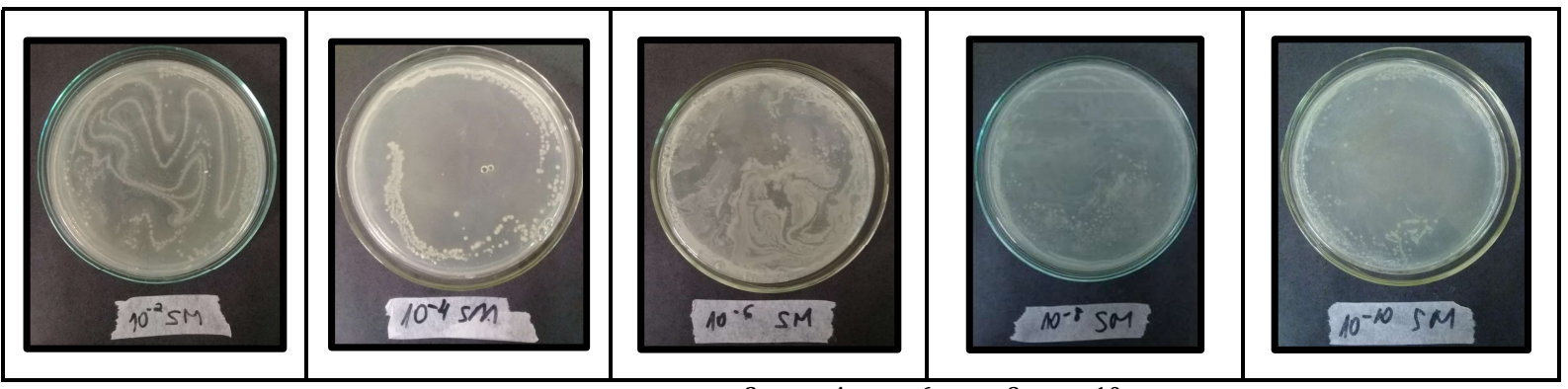

Figura 2: Resultado de uma replicação das diluições $10^{-2}, 10^{-4}, 10^{-6}, 10^{-8}, 10^{-10}$ do extrato de folhas cultivado em solo misto com suspensão bacteriana

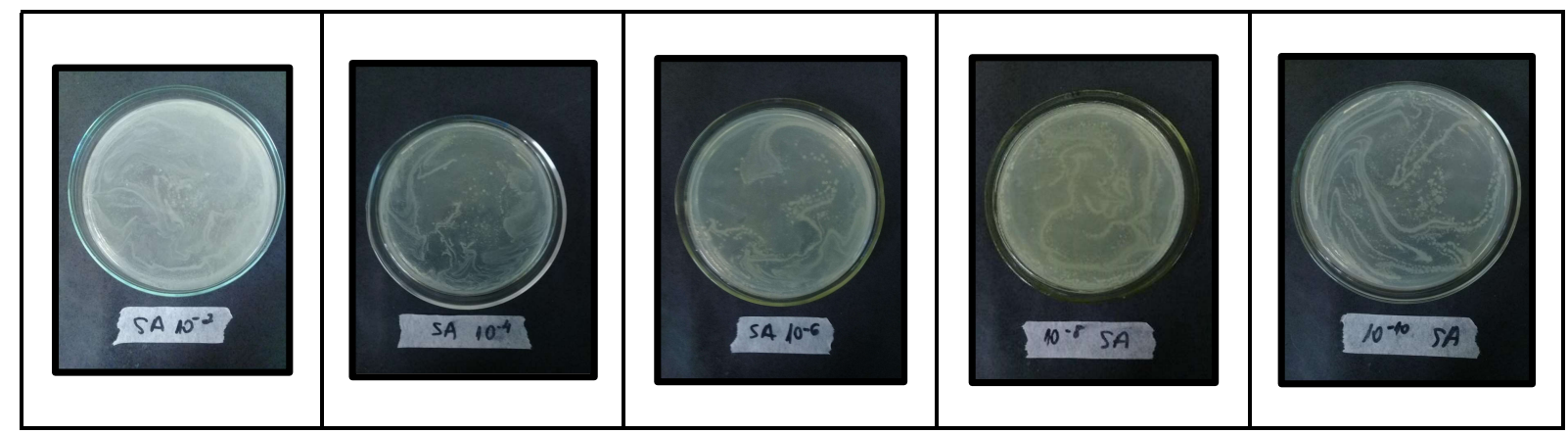

Figura 3: Resultado de uma replicação das diluições $10^{-2}, 10^{-4}, 10^{-6}, 10^{-8}, 10^{-10}$ do extrato de folhas cultivado em solo arenoso com suspensão bacteriana

Como esperado pela avaliação inicial da turvação e da absorbância, utilizando o método de semeadura Pour Plate não foi possível fazer a contagem pois para todas as diluições dos dois tipos de extratos observou-se um crescimento bacteriano por todas as placas petri, ultrapassando 10.000 UFC. 
Consequentemente, as diluições do extrato com concentração inicial de $0,28 \mathrm{~g} / \mathrm{mL}$ não mostraram ação bactericida ou bacteriostática contra o pool de bactérias presentes em dejetos bovinos neste experimento.

Ações antimicrobiana de extratos dos cones, como outras ações farmacológicas, são conhecidas e estudos mais recentes indicam também o potencial das folhas como fonte de compostos fenólicos antioxidantes e antimicrobianos (ABRAM et al., 2015; BOCQUET et al., 2018). Abram et al. (2015) avaliaram a ação bactericida de extratos dos cones e folhas de lúpulo contra bactérias Gram positivas e negativas, observando que extratos dos cones se mostraram mais eficientes ao combater o primeiro grupo do que os de folha. Para as bactérias Gram negativas, a ação foi moderada para ambos extratos.

Já Butu et al. (2016), ao testar a capacidade bactericida do extrato de cones de lúpulo contra Staphylococcus aureus, Bacillus subtilis, Pseudomonas aeruginosa e Escherichia coli, sendo as duas primeiras Gram positivas e as duas últimas Gram negativas, observaram maior eficiência contra a B. subtilis e menor contra a P. aeruginosa e foi constante para E. coli e S. aureus. Weber et al. (2019) constatou a eficiência do extrato de lúpulo contra Propionibacterium acnes (P. acnes) e Staphylococcus aureus (S. aureus), duas bactérias Gram positivas.

Quanto às condições de armazenamento e tempo de estocagem, o presente estudo foi semelhante ao apresentado por Butu et al. (2016). Eles observaram que os extratos armazenados em recipientes escuros e selados exposto a temperatura ambiente por dois meses ou em refrigerador por quatro meses, mantiveram as propriedades antimicrobianas. Ou seja, contanto que o recipiente siga as características citadas, a capacidade antimicrobiana não é afetada.

Em relação ao solvente, o presente estudo usou água e extração por infusão, diferente de Butu et al. (2016) que para obter o extrato dos cones, utilizou ultrassom e como solvente etanol 70\%, em uma relação de 1:10 entre solvente e material vegetal, assim como Santos (2018), com a diferença que o extrato foi obtido das folhas de lúpulo. Já Abram et al. (2015) utilizaram extratos etanólicos dos cones e folhas em banho-maria a 60 ㄷ $\mathrm{C}$ por $24 \mathrm{~h}$, com agitação constante em shaker a $170 \mathrm{rpm}$, método semelhante ao usado neste trabalho, diferenciando-se apenas quanto ao solvente.

A presença de poucas glândulas lupulinas nas folhas de lúpulo, concomitantemente com a forma de obtenção do extrato (solvente utilizado) e a não utilização de bactérias específicas podem justificar a falta de efeito antimicrobiano significativo, impossibilitando a determinação da concentração inibitória mínima. Santos (2018) e Abram et al. (2015) constataram a presença dos componentes fenólicos e flavonoides em extratos das folhas de lúpulo, porém em menor quantidade ao comparar com os cones, o que indica consequentemente, baixo teor de alfa e beta ácidos, os quais são os principais agentes bactericidas. Mesmo assim, há indícios que as folhas possam ser utilizadas para este fim, sendo necessário mais estudos neste sentido.

A luz do alcance da literatura avaliada, ao que tange a eficiência da ação antimicrobiana, observa-se que os extratos de lúpulo, principalmente os feitos a partir dos cones, mostraram maior eficácia contra bactérias específicas, principalmente para o grupo Gram positiva. No presente estudo não foi observado efeito bacteriostático, no entanto, foram realizados testes contra um pool de bactérias isoladas dos dejetos, 
envolvendo diferentes tipos de bactérias (Gram positivas e negativas). Assim, sugere-se para estudos futuros a avaliação do efeito em bactérias específicas dos dejetos.

\section{CONCLUSÕES}

A ação antibacteriana para o pool de bactérias de dejetos bovinos utilizando o método de obtenção de extrato, proposto neste estudo, a partir das folhas de lúpulo não foi efetiva. No entanto, dado os poucos trabalhos avaliando as folhas, destaca a importância de estudos, quanto à metodologia proposta, para maximizar os componentes fenólicos dos extratos em diferentes condições experimentais, bem como a avaliação em bactérias isoladas dos dejetos.

\section{REFERÊNCIAS}

ABRAM, V.; ČEH, B.; VIDMAR, M.; HERCEZI, M.; LAZIć, N.; BUCIK, V.; MOžINA, S. S.; KOSIR, I. J.; KAC., M; DEMŁAR, L; ULRIHA, N. P.. A comparison of antioxidant and antimicrobial activity between hop leaves and hop cones. Industrial Crops And Products, Ljubljana, v.64, p.124-134, 2015. DOI: http://dx.doi.org/10.1016/j.indcrop.2014.11.008

ALMAGUER, C.; SCHÖNBERGER, C.; GASTL, M.; ARENDT, E. K.; BECKER, T.. Humulus lupulus- a story that begs to be told. A review. Journal of The Institute Of Brewing, Cork, v.120, n.4, p.289-314, 2014. DOI: http://dx.doi.org/10.1002/jib.160

ARIAS, M. V. B.; CARRILHO, C. M. D. M.. Resistência antimicrobiana nos animais e no ser humano. Há motivo para preocupação?. Semina: Ciências Agrárias, Londrina, v.33, n.2, p.775-790, 2012. DOI:

http://dx.doi.org/10.5433/1679-0359

BOCQUET, L.; SAHPAZ, S.; HILBERT, J. L.; RAMBAUD, C.; RIVIÈRE, C. Humulus lupulus L., a very popular beer ingredient and medicinal plant: overview of its phytochemistry, its bioactivity, and its biotechnology: overview of its phytochemistry, its bioactivity, and its biotechnology. Phytochemistry Reviews, Basel, v.17, n.5, p.1047-1090, 2018. DOI: http://dx.doi.org/10.1007/s11101018-9584-y

BUTU, A.; RODINO, S.; BUłU, M.. The antimicrobial activity of humulus lupulus I. depending. Analele Stiint. Univ. Al. I. Cuza lasi, Sect. li A. Biol. Veget., Bucharest, v.2, n.62, p.47-52, 2016.

CHADWICK, L. R.; PAULI, G. F.; FARNSWORTH, N. R.. The pharmacognosy of Humulus lupulus L. (hops) with an emphasis on estrogenic properties. Phytomedicine, Chicago, v.13, n.1-2, p.119-131, 2006. Dol:

http://dx.doi.org/10.1016/i.phymed.2004.07.006.

FRANCO, L.; SÁNCHEZ, C.; BRAVO, R.; RODRÍGUEZ, A. B.; BARRIGA, C.; ROMERO, E.; CUBERO, J.. The sedative effect of non-alcoholic beer in healthy female nurses. Plos One, San

Francisco, v.7, n.7, p.133-139, 2012. DOI:

http://dx.doi.org/10.1371/journal.pone.0037290

KOETTER U.; BIENDL, M.. Hops (humulus lupulus): a review of its historic and medicinal uses. The Journal of the

American Botanical Council, v.87, p.44-57, 2010.
LOGAN, I.; MIRANDA, C.; LOWRY, M.; MAIER, C.; STEVENS, J.; GOMBART, A.. Antiproliferative and cytotoxic activity of xanthohumol and its non-estrogenic derivatives in colon and hepatocellular carcinoma cell Lines. International Journal of Molecular Sciences, Corvallis, v.20, n.5, p.1203-1203, 2019. DOI: http://dx.doi.org/10.3390/ijms20051203.

NASCIMENTO, V. C.. Processo de Biodigestão Anaeróbia: protocolo piloto para a identificação de patógenos presentes em dejetos bovinos. In: CONGRESSO DE INICIAÇÃO DE CIENTÍFICA DA UNESP, 30. Anais. Botucatu: UNESP-PROPE, 2017.

NOVAES, R. H.; RODRIGUES, S. A.; SARNIGHAUSEN, V. C. R.; DAL PAl, A.. Aspecto de cultivo, econômicos e históricos do lúpulo. In: ENCONTRO BRASILEIRO DE PESQUISADORES E PRODUTORES DE LÚPULO - ENBRALÚPULO, 1. Anais. Botucatu: UNESP, 2019.

SANTOS, V. A.. Estudo fitoquímico e atividade antioxidante do extrato e frações das folhas de Humulus lupulus $L$. (Cannabaceae). Monografia (Bacharelado em Farmácia) Universidade Federal de Ouro Preto, Ouro Preto, 2018.

SCHICK, D.; SCHWACK, W.. Detection of estrogen active compounds in hops by planar yeast estrogen screen. Journal of Chromatography A, Stuttgart, v.1532, p.191-197, 2018. DOI: http://dx.doi.org/10.1016/j.chroma.2017.11.069

SOUSA, F. G. G.; GUIMARÃES, J. J.; SOUSA, R. L.; DAL PAI, A.; RODRIGUES, S. A.; SARNIGHAUSEN, V. C. R.. Determinação do consumo hídrico do lúpulo cultivado em ambiente protegido. In: ENCONTRO BRASILEIRO DE PESQUISADORES E PRODUTORES DE LÚPULO - ENBRALÚPULO, 1. Anais. Botucatu: UNESP, 2019.

SOUSA, M. J.. Obtenção de plantas de Humulus lupulus L. resistentes a vírus. Tese (Doutorado em Biotecnologia Vegetal) - Universidade de Lisboa Faculdade de Ciências, Lisboa, 2005.

SOUZA, A. G.; SARNIGHAUSEN, V. C. R.; GROTTO, R. M. T.; NASCIMENTO, V. C.. Padronização do protocolo de coleta de dejetos bovino para biodigestão anaeróbia e determinação da diluição ideal para posterior análise microbiológica. In: CONGRESSO DE INICIAÇÃO DE CIENTÍFICA DA UNESP, 30. 
Anais. Botucatu: UNESP-PROPE, 2017.

SUGIYAMA, R.; ODA, H.; KUROSAKI, F.. Two distinct phases of glandular trichome development in hop (Humulus lupulus L.). Plant Biotechnology, Toyama, v.23, n.5, p.493-496, 2006. DOI: https://doi.org/10.5511/plantbiotechnology.23.493.

WEBER, N.; BIEHLER, K.; SCHWABE, K.; HAARHAUS, B.; QUIRIN, K.; FRANK, U.; SCHEMPP, C. M.; WÖLFLE, U.. Hop extract acts as an antioxidant with antimicrobial effects against propionibacterium acnes and staphylococcus aureus. Molecules, Freiburg, v.24, n.2, p.223-223, 2019. DOI: http://dx.doi.org/10.3390/molecules24020223

ZANOLI, P.; ZAVATTI, M.. Pharmacognostic and pharmacological profile of Humulus lupulus L. Journal Of Ethnopharmacology, Modena, v.116, n.3, p.383-396, 2008. DOI: http://dx.doi.org/10.1016/i.jep.2008.01.011

A CBPC - Companhia Brasileira de Produção Científica (CNPJ: 11.221.422/0001-03) detém os direitos materiais desta publicação. Os direitos referem-se à publicação do trabalho em qualquer parte do mundo, incluindo os direitos às renovações, expansões e disseminações da contribuição, bem como outros direitos subsidiários. Todos os trabalhos publicados eletronicamente poderão posteriormente ser publicados em coletâneas impressas sob coordenação da Sustenere Publishing, da Companhia Brasileira de Produção Científica e seus parceiros autorizados. Os (as) autores (as) preservam os direitos autorais, mas não têm permissão para a publicação da contribuição em outro meio, impresso ou digital, em português ou em tradução. 